\title{
Construcción del "verdadero" hombre en los textos escolares utilizados en las escuelas primarias argentinas
}

\author{
Autores: Lic. Myrian Andrada \& Lic. Pablo Scharagrodsky \\ Institución: Universidad Nacional de Quilmes. Programa de \\ Investigación: Sujetos y políticas en educación
}

\section{Dirección Postal: Roque Sáenz Peña 180 Bernal, Argentina (B1876BXD). Tel: (5411) 4365-7100 Int. 202 Fax: (5411) 4365-7182 \\ E-mail: mandrada@unq.edu.ar y pas@unq.edu.ar}

\section{Resumen}

Este estudio reconstruye las cualidades que asume la infancia en situación de escolarización ${ }^{1}$, a partir de los modelos infantes masculinos identificados en los textos. En este sentido, la masculinidad no es una esencia sin tiempo, que reside en lo profundo del corazón, algo eterno o innato producto de cierta composición biológica del macho humano. En los textos analizados se identifican ciertos ritos, usos y posiciones corporales, cierta iconografía que instala una carrera para convertir al niño, muchachuelo, muchachito, muchacho, u hombrecito en un "verdadero" hombre. Dicho pasaje, que está acompañado de ciertas pruebas, responsabilidades, mandatos y usos corporales que se presentan como exclusivos de un niño -pero no de la niña- y que debía asumir en relación con su propio cuerpo y con el de los otros. Tal como se observa a través de los textos escolares, la masculinidad es un conjunto de significados siempre cambiantes (y siempre disputables) que construimos a través de nuestras relaciones con nosotros mismos, con los otros, y con nuestro mundo.

En las últimas décadas del siglo $\mathrm{XX}$, los requisitos para llegar a ser hombre sufren una serie de mutaciones, asociadas por una parte, a cambios en la disposición espacial y a las características que el cuerpo masculino presenta en las imágenes. Y por otra parte, a la ausencia de lecturas dedicadas exclusivamente a resaltar cualidades que un niño varón debía alcanzar y hacer suyas para llegar a constituirse en un "verdadero" hombre. Si como ha afirmado S. de Bouveaur "no se nace mujer se llega a serlo", tampoco se nace varón se llega a serlo. Tal proceso es el que se intenta indagar en este trabajo.

\footnotetext{
${ }^{1}$ Para un desarrollo amplio y desde una perspectiva histórica acerca de los orígenes y la situación actual del concepto de infancia moderna, pueden consultarse los trabajos: Narodowski, M. (1994). Infancia y poder. La conformación de la pedagogía moderna, Bs. As. : Aique y Narodowski, M. (1999) Después de clase. Desencantos y desafíos de la escuela actual. Bs. As. : edu $\backslash$ causa, Novedades Educativas.
} 
Palabras Claves: textos escolares argentinos- masculinidades- modelos de infancia- escolarización- iconografía.

\section{Introducción}

El presente trabajo indaga en los procesos que configuran ciertos modelos de infancia desde una perspectiva generizada. Los doscientos treinta textos escolares ${ }^{2}$ que constituyen la fuente de análisis, están destinados a los alumnos de las escuelas primarias argentinas. Se dirigen a los distintos grados del nivel primario, aunque se focaliza el análisis principalmente en los textos de tercer a sexto grado -este recorte obedece a la evidencia encontrada en relación al tema de estudio-. El periodo abordado se ha situado desde las primeras décadas del siglo XX hasta los últimos años de dicho siglo. Tal periodización responde a una dinámica micropolítica vinculada estrictamente con la producción y distribución de saberes que moldean a la infancia generizada en situación de escolarización.

El análisis ha sido abordado a partir de la iconografía y del lenguaje que acompaña a dichas imágenes en los textos escolares de aquellas épocas. Los aspectos considerados han sido: el uso de la vestimenta: zapatos, medias, ropa interior (ausente), cabello, pantalones, remeras, ropa en general (limpia, prolija, sucia, desprolija) etc.; los usos del cuerpo como resultado de un proceso escolar de institucionalización: ciertos desplazamientos, ciertos movimientos corporales, ciertas posturas, ciertas ubicaciones de las manos en relación al cuerpo, ciertos gestos, cierta relación entre el cuerpo y el espacio arquitectónico, cierta relación entre el cuerpo y el tiempo escolar.

\section{Hablando y dibujando masculinidad y femineidad}

La evidencia obtenida en este estudio, permite afirmar que a través de los textos escolares, se construye cierta masculinidad y cierta femineidad. Específicamente, a partir del análisis del lenguaje utilizado en los textos escolares se han identificado las siguientes continuidades y rupturas:

1) Desde las primeras décadas del siglo $X X$ hasta aproximadamente la década del 70 del mismo siglo, el control del aseo sobre el infante ha sido ejercido por la figura materna: es decir por la mamá o madre. Tal control ha recaído tanto para niños como para niñas. Sin embargo, los términos que acompañan a cada género son distintos. En caso de estar acompañado en el baño es la mamá quien esta

\footnotetext{
${ }^{2}$ En el Anexo I que acompaña este trabajo puede encontrarse el listado y fechas de cada uno de textos consultados. Cabe aclarar que se trata solo de libros destinados a la enseñanza de la lectura.
} 
corporalmente más cerca y están literalmente en contacto corporal. La mamá (íntegramente vestida y tapada, peinado con rodete o pelo recogido) acaricia la cabeza de su hijo o le toma la mano. El padre (tiene bigotes y una pipa signos de que es un hombre) cuando aparece en las imágenes de aseo esta en una actitud corporal erguida y mas distante en relación a la mamá. La madre tiene el cuerpo no erguido sino en forma de cubrir al niño -idea de protección, intimidad y afectividadLa postura del niño, en cambio, da la sensación de ser receptiva. Nuevamente es la madre quien lava y seca al niño. Esta tendencia comienza a decrecer a partir de la década del 60 del siglo XX.

2) Abundan las prescripciones morales que están referidas a ciertos hábitos, costumbres y comportamientos: lavarse, peinarse, despertase, sentarse, ordenarse, limpiarse, dormirse, ser educado, ser valiente, ser obediente, respetar al prójimo, ser trabajador, utilizar el tiempo en formas no ociosas, ser feliz, ser simpático, ser moralmente limpio, ser modesta, ser suave, ser frágil, ser decorosa, ser bonita, ser prolija, no ser desordenada, etc. Todos estos modos que configuran un estilo de vida determinado se "encarnan" en los cuerpos en forma diferencial. En este punto la diferencia se instala como sinónimo de jerarquía. Ser niña es diferente a ser niño.

3) Desde fines de la década del 60 y principios de los años 70 del siglo $\mathrm{XX}$, paulatinamente, se han identificado ciertas rupturas en el lenguaje de los textos escolares. Entre los quiebres más significativos podemos mencionar un cierto "relajamiento": de la disciplina, el orden, la obediencia y la corrección se pasa a otras regulaciones corporales con términos como: descubrimiento, creatividad, diálogo -los niños emiten opiniones propias, discuten con los adultos-, afianzamiento, vivenciar o expresar. Otras tantas 'fisuras' se han identificado a partir de estos mismos años para el caso de los modelos de familias (Wainerman y Heredia, 1999) y particularmente en relación a la infancia, la aparición del conflicto en las lecturas dedicadas a las familias y cambios en la especificidad del amor maternal y el amor paternal (Andrada, 2000).

En función del análisis iconográfico en los textos escolares se han identificado las siguientes continuidades y rupturas: 
1) Los textos escolares desde principios de siglo $X X$ hasta mediados de la década del 70 muestran recurrentemente la figura de varones, tal como ya han demostrado otros investigadores (Wainerman y Heredia, 1999), desde una perspectiva de género. Sin embargo, cuando aparecen figuras femeninas las mismas refieren a ciertos mandatos muy acotados, vinculados a la maternidad y al espacio doméstico (Andrada, 2000). Asimismo, la construcción de una cierta masculinidad esta asegurada a partir de actitudes, gestos, desplazamientos y mandatos vinculados a ciertos roles. En el niño ser valiente, ser caballero o ser viril; en el padre, ser proveedor, ser el ejemplo o estar laboralmente ocupado en el espacio publico. Cuando se muestran a niñas, sus actitudes, gestos, desplazamientos y mandatos son claramente constructores de femineidad "subordinada": laboralmente ocupada en el espacio privado y/o doméstico.

2) El aseo del cuerpo es dirigido a ciertas partes del mismo y no a otras: cara, orejas, cuello, dientes y manos. Las imágenes del aseo corporal están recurrentemente protagonizadas por niños, mas que por niñas. Por otra parte, en ningún momento se mencionan partes vinculadas al aparto genital de ninguno de los sexos: a las axilas, al ano, a los senos, etc. A su vez, las menciones sobre 'pulcritud' en relación a las niñas, son para destacar el cuidado y delicadeza que ellas tienen para con su ropa y objetos personales.

3) Desde principios de siglo hasta principios de la década del 70, los cuerpos aseados son mostrados cerca de un lavatorio con espejo (no de un bidé) o una silla. Se insiste hasta el cansancio en la asociación limpieza civilización ${ }^{3}$ :

"El hombre civilizado es aquel que dedica gran parte de su atención al aseo personal. El hombre salvaje apenas se acuerda de la higiene. Lavaos niños!, higienizad vuestros cuerpos para que los poros de la piel cumplan su tarea. No os parezcáis al salvaje" [Macias, J. (1915) Ilusión. Bs. As.: Estrada]

\footnotetext{
${ }^{3}$ Proceso que ha sido ampliamente analizado desde una genealogía, por Norbert Elías (1987) en su clásico trabajo: El proceso de la civilización. México: FCE.
} 
Las imágenes de aseo continúan vigentes durante las décadas del 40 y del 50 del siglo XX. Así, se citan las mismas partes del cuerpo que en décadas anteriores aunque se hace más hincapié en el ritmo y la frecuencia con que dichas acciones deben llevarse a cabo. En forma reiterada se indican los momentos:

"Manuel y Benito son muy aseados. Al levantarse se lavan y peinan con esmero. Después toman el desayuno...Quienes los ven pasar piensan: qué nenes tan lindos y aseados! [Eguren, S. (1946) Primeras Luces. Bs. As.: Independencia]

"Dardo se levanta siempre temprano. Después de darse un buen baño de lluvia, se viste, se limpia los dientes y las uñas, y luego, antes de tomar el desayuno, hace un poco de gimnasia. Dardo llegará a ser un hombre ágil y vigoroso. Su fortaleza será el escudo de su salud" [Luchía Puig, D. (1945) Delantales blancos. Libro de lectura para segundo grado, Bs. As.: Marcos Sastre]

\section{Y también la frecuencia:}

"Yo me lavo la cara dos veces por día.", "yo me lavo la cabeza dos veces por semana en invierno, y mas a menudo en verano". [Escuelas Pías, Argentina. (1940) Brisas. Libro de lectura para tercer grado. Bs. As.: Kapelusz]. El niño se asea peinándose el cabello con un cepillo: "-Hoy olvidé de peinarme- dice José. -¿Sí? Pues yo acabo de hacerlo- contesta Héctor. -Esto del aseo- agrega José- me resulta divertido." [Escuelas Pías, Argentina. (1940) Brisas. Libro de lectura para tercer grado. Bs. As.: Kapelusz].

A partir de la década del 60, la importancia asignada al aseo y la higiene ${ }^{4}$ disminuye en las imágenes y en el lenguaje utilizados en los textos. Vale decir, la problematización ${ }^{5}$ de un cuerpo limpio comienza a decrecer apareciendo lecturas e imágenes más vinculadas al juego de los niños, travesuras y otras actividades en la escuela o en el interior del hogar, pero con ausencia significativa a las relacionadas con la limpieza corporal.

\footnotetext{
${ }^{4}$ Términos como el aseo y la higiene dan paso a otros cuya proyección semántica es diferente, como el caso de la salud o la vida saludable. Cita de la tesis de Pablo

${ }^{5}$ El concepto de "problematización", es tratado por autores como Foucault (1988, 1989 y 1996) y Larrosa (1998). Algunos trabajos recientes que abordan el estudio del curriculum en Argentina, recurren a este concepto (Palamidessi, M., 2000) en tanto una problematización hace que -en ciertas condiciones y en ciertos momentosse nos manifieste un objeto, una cuestión o un aspecto que hasta entonces no era percibido como foco de atención. Y es en ese sentido que una problematización tiene su historia, incluso pueden perdurar durante siglos o tener una existencia efímera.
} 
4) En las imágenes de los cuerpos, desde principios de siglo hasta principios de la década del 70, se manifiestan ciertas tendencias en relación a su uso ${ }^{6}$. En este sentido, el cuerpo del niño aparece siempre erguido, levemente inclinado hacia al frente y en menor medida hacia atrás, y con una cierta postura. Nunca aparece acostado o arrodillado. En el varón, el pelo esta siempre corto y en general es de color oscuro (negro o gris). Tampoco hay pelos visibles (vello) en el resto del cuerpo. En la figura del padre los pelos se instalan en el cuerpo, como por ejemplo en los bigotes. En la niñita el cuerpo también aparece erguido, aunque en general el tamaño de ella es menor al de él. El pelo en general es largo y tiene más rizos. Tampoco hay pelos visibles (vello) en el resto del cuerpo. La figura de la madre es menor en tamaño a la del padre y sus manos sujetan a los hijos. Pareciera que las manos de la madre tienen un mandato corporalmente afectivo. No sucede lo mismo con el padre. Pareciera que la expresión en el rostro de la mama es más afectiva.

Los niños no se tocan corporalmente. Uno sostiene una rama. Los brazos nunca son levantados, casi siempre miran hacia abajo, tal como se observa en textos como Girasoles en su edición de 1952. En este mismo libro y de igual forma que en la mayoría de los analizados, los niños visten guardapolvo blanco (con un cinturón y bolsillo, moño en el cuello y muchos botones, muy similar al de las niñas) y entre las conversaciones se mencionan ciertas cualidades como: arriesgados, ánimo de emprender alguna aventura grandiosa, remontar ríos caudalosos, leer hazañas, etc.

5) Las imágenes de la vestimenta en el niño presentan una tendencia clara. Desde principios de siglo hasta principios de la década del 70 los niños (y no las niñas, que usan polleras en todas las imágenes analizadas) usan pantalones hasta la rodilla, en general de color oscuro. Esta práctica exclusiva del varón, es un antecedente previo al uso de los pantalones largos, los cuales garantizan la carrera hacia una determinada masculinidad:

"Ponerse pantalones largos obliga a portarse muy bien... Manuel Ramón debió querer empezar a ser hombre, tenía derecho a fumar a demorarse en la calle, a faltar en la escuela, a buscar amigos mayores que el y a salir con ellos..."

\footnotetext{
${ }^{6}$ Ver Buenfil Burgos. R. "Horizonte posmoderno y configuración social" En Alba, A. (comp), Posmodernidad y Educación. México: Editorial Porrúa. Ningún discurso es fijo o estático sino relacional. Cada término adquiere sentido en función al juego del lenguaje en el que esta inmerso.
} 
"Yo no me pondré pantalones largos para parecer hombre; me los pondré para comenzar a ser hombre". 7 [Capdevilla Y Velloso (1957). Ruta Gloriosa. Bs. As.: Kapelusz]

“-Señor Pérez ya es tiempo de que usted se ponga pantalones largos- todo el mundo se dispuso a obedecerle. En vano apunte yo, tímidamente: -Pero señor, aún soy muy chico... - ¿Y que importa señor? dijo mirándome fría y severamente-. ¿Piensa usted, acaso, graduarse con pantalones cortos?- Y me endilgó un largo discurso sobre la estrecha relación que existe entre la autoridad magistral y la longitud de los pantalones". [Tolosa, O. (1954) Al pasar, Bs. As.: Estrada]

En esta misma línea, otras lecturas tienen como tema principal, el ir a comprar un traje -es importante aclarar que en las imágenes, los trajes para niños si bien pueden incluir camisa, saco y corbata, el pantalón no es el 'clásico' pantalón largo sino corto o hasta la rodilla- para el niño y en este caso es el padre quien lo acompaña:

"-Papá, cómprame un traje- pidió Cachito a su buen padre.

-Papá, este traje marinero es el que mas me agrada.

-Bien, hijito, veo que tienes buen gusto; es bonito y te sienta bien- y muy complacido le compró el traje deseado. [Sanz, H. (1949) Mi Tesorito. Primer libro de lectura corriente, Bs. As.: kapelusz]

Por otra parte, el resto de la vestimenta usada presenta la siguiente tendencia: la remera, en general es blanca y los zapatos son cerrados (en décadas posteriores aparecen zapatos con cordones) y de color negro o grises. Las medias, a veces recogidas sobre el tobillo y otras hasta casi la rodilla. Las mismas son de color negro. Salvo la parte del cuerpo que va desde la rodilla hasta los tobillos, el resto del cuerpo esta cubierto. También las manos y la cara están descubiertas. La remera esta arremangada hasta el codo. Hay imágenes de varones con ciertos uniformes como el de "marinerito". A principios de la década del 70 del siglo XX, las imágenes muestran a niños con pantalones cortos y también con pantalones largos. Ello podría sugerir que ciertos rituales que convertían a los niños en verdaderos hombres, como el de los pantalones largos, no aparecen. No obstante ello no implica vacío de rituales acerca de 
la masculinidad en el ámbito escolar. Lo que si se ha podido constatar es que los requisitos para llegar a ser hombre sufren una serie de mutaciones, asociadas por una parte, a cambios en la disposición espacial y a las características que el cuerpo masculino presenta en las imágenes.

Por otra parte, se ha identificado una pronunciada ausencia de lecturas dedicadas exclusivamente a resaltar cualidades que un niño varón debía alcanzar y hacer suyas para llegar a constituirse en un "verdadero" hombre.

Un proceso similar ocurre para el caso del "primer reloj con cadena o pulsera", se han identificado lecturas dedicadas a resaltar la importancia del cumplir con los horarios y también las que muestran al abuelo o al padre regalando al niño -y no a la niña- el reloj que había pertenecido a su progenitor o a su abuelo durante su "juventud":

"Pero lo que no sabe ninguno de ustedes- intervino el papá- es que el reloj será siempre el testigo de nuestra actividad o tal vez el inoportuno de nuestra pereza; pero en todos los casos, hijos míos, un testigo utilísimo."

"Porque nos recordará la observancia de la puntualidad, que, si para él es sencilla obligación mecánica, para nosotros es un verdadero deber moral." [Ruiz, López, R. (1941) Caminito de luz. Libro de lectura para cuarto grado. Bs. As.: Kapelusz]

"-Ven para acá Rubén. No he olvidado que hoy cumples doce años...Aquí tienes mi libreta de calificaciones escolares...Aquel reloj había señalado la actividad de una vida honesta y laboriosa. El reloj podía estar tranquilo: seguiría marcando horas fecundas de su vida, como lo había hecho con las serenas y fructíferas del honrado anciano. [Davel de Dambrioso, R.. (1941) De mi tierra, tercer libro de lectura. Bs. As. Estrada]

\section{El pasaje de niño, muchacho, muchachuelo, a hombre: :"Macho" se nace o se hace?}

La iconografía y el lenguaje que se refiere a la infancia escolar (entre los 8 y 12 años) presenta ciertas características. Con respecto al lenguaje, una batería de lexemas que establecen proyecciones semánticas diversas. Dicha variación esta vinculada, por un lado, con el juego del lenguaje en relación al resto de los términos que conforman

\footnotetext{
${ }^{7}$ La cursiva es de la fuente original.
} 
un enunciado ${ }^{8}$, y por el otro, con la especificidad propia del término. Vale decir, niño, muchachuelo, chicuelo, muchacho y hombre adquieren un sentido con atributos y propiedades distintas. El niño, el muchacho, el muchachuelo se diferencian, en los textos escolares, no sólo en su aspecto corporal, sino también en la vestimenta utilizada $\mathrm{y}$, en especial, en los mandatos sociales que le son atribuidos. Esto último implica una fuerte responsabilidad de la institución escolar en la contribución a la construcción de una cierta masculinidad y femineidad. Las tendencias identificadas en los textos escolares permiten determinar que: es un deber del niño ser feliz -una tendencia semejante se ha identificado en un trabajo anterior, en relación a las cualidades de los modelos de familias que presentan los textos ${ }^{9}-$, no ser cobarde, soportar las diversidades de la vida, "ser pacientes, y aceptar con paciencia el billete que nos toca en la lotería de la vida" [De Toro y Gómez C. (1926) El Hogar de Todos. Bs. As.: Kapelusz], ser sereno, esforzarse, no ser travieso, jugar pero también estudiar: "A los muchachos les gusta jugar, y eso no es malo; pero también debe gustarles ir a la escuela y estudiar. Hay tiempo para todo: para jugar y para estudiar." [Vásquez A. (1910) Serie graduada de libros de lectura. Libro Segundo. Bs. As.: Ceppi, Muller \& Cía]. La simpatía y la fortaleza corporal, son también cualidades resaltadas como propiedades de los varones:

"La simpatía es una fuerza comparable a la del imán, por su poder de atracción. Entran en ella varias cualidades que forman la verdadera superioridad de unas personas sobre otras. En la simpatía hay sinceridad de sentimientos, modestia, firmeza, tolerancia..." [Almagro, J. (1929) El mundo que yo veo. Bs. As.: Independencia -Corporación argentina de publicaciones didácticas.]

"-Sóis pequeños, sois alegres, jugáis: estáis en la edad feliz." [De Toro y Gómez, C. (1932) La escuela y la vida. Bs. As.: Kapelusz]

\footnotetext{
${ }^{8}$ Alba, A., Educación y postmodernidad. Ningún discurso es fijo o estático sino relacional. Cada término adquiere sentido en función al juego del lenguaje en el que esta inmerso.

${ }^{9}$ A comienzos del siglo XX la figura de la madre es la única capaz de lograr el aumento de felicidad del hogar a través de diferentes acciones domésticas y la demostración de afecto, las madres monopolizan la ternura. En cambio, a partir de la segunda mitad de ese siglo se identifican discontinuidades en la hegemonía de ese modelo familiar, sustentadas en los cambios de sus integrantes, sus actividades y trabajos, cualidades personales y relaciones entre ellos. Desarrollo presentado en: Andrada, M. (2000, setiembre). Happy families according to the shoolbooks used in primary school in Argentina. Ponencia presentada en la XXII th. International Standing Conference for the History of Education, Alcalá de Henares.
} 
"Los varones protegen a sus hermanas, que son más débiles; en cambio las hermanas son como madrecitas que cuidan a sus hermanos en todo lo que es propio de una niña." [Martin, L. (1930) Nuevas sendas. Primer libro de lectura corriente. Bs. As.: Independencia]

Por el contrario, el hombre se diferencia del niño ya que le es asignado ciertos valores como: previsión, ahorro, tener un trabajo, escuchar atentamente, no ser ocioso, etc. Dichos atributos están fuertemente vinculados con la organización económico-productiva y también familiar. El modelo de familia es monolítico, unidimensional y con una compulsiva tendencia hacia la heterosexualidad.

A su vez, la imagen del hombre esta, en muchos casos representada por el padre, cuyas funciones son ser proveer de la familia con el sudor de su trabajo:

"El papá de Luisito y Zelmirita es un hombre alto, fornido, de anchas espaldas y rostro inteligente y varonil...Merced a sus hábitos de orden y economía; merced a su acendrado amor al trabajo; merced a sus vigorosas iniciativas y acrisolada ${ }^{10}$ honradez, se ha labrado una posición holgada..." [Montes V. (1909) La frase.. Bs. As.]

Ser el padre asegura ciertos mandatos como "dar lecciones". Por el contrario, la madre "brinda consejos" y en varias ocasiones se convierte en la mediadora para tomar alguna decisión entre el padre y el niño o la niña. Sin embargo, en los textos escolares, aparece el padre "con la ultima palabra".

Otra característica propia del hombre es no ser holgazán, ni ser haragán. Tales atributos son sinónimos de masculinidad denigrada. Así lo atestigua la evidencia encontrada:

"Los que están siempre ociosos, cuando llegan a hombres no sirven para nada" [Vásquez A. (1910) Serie graduada de libros de lectura. Libro Segundo. Bs. As.: Ceppi, Muller \& Cía]

"Del taller salió formado el ciudadano ya hombre, sin una mancha en su nombre, ni una sombra en su honradez. En el altar de la patria se formó buen ciudadano virtuoso, digno, cristiano, generoso y varonil...Honor al hijo del pueblo que en el trabajo se eleva y en él engrandece y prueba su abnegado corazón! [De Toro y Gómez, C. (1926) El Hogar de Todos. Libro de lectura para cuarto grado. Bs. As.: Kapelusz]

\footnotetext{
${ }^{10}$ El resaltado en itálica de esas palabras es del texto original y se incluye en la lectura el significado asignado a esos términos: fornido: robusto, varonil: fuerte, valeroso, hábitos: costumbres, acendrado: puro, sin manchas, ni defecto, acrisolada: purísima.
} 
No sólo existe una diferenciación entre el niño, el muchacho, el muchachuelo y el hombre. La niña también es configurado como tal. No obstante, el proceso es absolutamente distinto. Así, en los textos se les asignan cualidades y acciones como las siguientes:

"A Juana le compran lindos vestidos y sombreros" [De Toro y Gómez, C. (1926) El Hogar de Todos. Libro de lectura para cuarto grado. Bs. As.: Kapelusz]. Debe ser elegante. Todos estos comportamientos son a la vez, tanto físicos como morales. Así lo confirman numerosas frases:

"La única superioridad que debemos tener en cuenta es la superioridad moral." [De Toro y Gómez, C. Ibid]

Asimismo, ser mujer implica ser estudiosa, obediente y ordenada. También las actividades lúdicas constituyen potentes prácticas que configuran subjetividad generizada. Las imágenes muestran a los niños con una variedad de movimiento mayor que en las niñas. Asimismo las niñitas son caracterizadas de la siguiente manera:

"La niña estudia con empeño, escucha atentamente las explicaciones de la maestra y hace sus deberes con prolijidad." [De la Vega, L. (1941) Entre amigos. Texto para tercer grado, Bs. As.: Independencia.]

"Una niña debe ser dulce, suave, cariñosa siempre.. .siempre con buenos modales y con discreción, pues nada hay mas feo en una niña y en una mujer, que la falta de femineidad. [Estrella Gutierrez, F., y Barrio De Estrella Gutierrez, J. (1942) Días de Infancia. Libro de lectura para cuarto grado. Bs. As.: Kapelusz]

Las niñitas son limpias y lindas. En cambio, el niño es un destrozón de ropa y calzado:

"Tenía yo nueve años, y era, como la mayoría de los chicos de esa edad, un soberano destrozón de ropa y calzado." [Berrutti, J. (1918) Estudio. Libro de lectura para tercer grado. Bs. As.: Estrada]

"Pero, hijo!. Hay que tener mas cuidado con las cosas; Bueno ya está pegado el botón." [Berdiales, G. y Inchauspe (1944) Actividades y conocimientos Bs. As.: Kapelusz] "Carmencita no tiene más que un guardapolvo. Todos los lunes lo lleva limpio y planchado. Lo cuida para que se conserve sin manchas toda la semana. [Arena, L. (1956) Rama Florida. Primer libro de lectura corriente. Bs. As.: Estrada] 
Es posible plantear como hipótesis, a partir de las imágenes y del contenido de las lecturas, que de niña o niñita se pasa directamente a ser mujer o madre y toda la serie de 'pasajes' identificados son de exclusiva pertenencia masculina, en otra palabra de los niños. Los ritos de pasaje de niño a varón se manifiestan en "los pantalones largos"11, "el reloj pulsera", "el ponerse el primer traje con corbata y pantalones largos", "el primer sombrero elegante", "el fumar", "la primera entrevista laboral", etc. En cambio, el camino de niñita a mujer, en los textos escolares, pareciera ser un pasaje con menos desafíos y cambios. ${ }^{12}$ No se ha encontrado evidencia empírica de hechos similares a los del varón. Pareciera que de la niñita a la madre hay un solo pasaje: el matrimonio y el hogar.

Si bien, este trabajo está en su etapa inicial, ya que se pretende continuar con este tipo de abordaje realizando un análisis más exhaustivo en relación al uso del lenguaje, merecen destacarse ciertas cuestiones terminológicas. Se identifican términos como: muchachito y muchachuelo y no sus opuestos muchachita y muchachuela. El "muchachuelo" tal como se encuentra en textos como: Estudio. Libro de lectura en su edición de 1918 y en especial el muchacho, transgreden, realiza acciones que no están permitidas al niño. Entre ellas, tirar piedras a un perro como se observa en el texto Lectura Expresiva en su edición de 1909, fumar un cigarrillo, tal como se muestra en Compañero, entre otras. La vestimenta cubre toda la pierna ocultando los pelos de la misma. La vestimenta comienza a diferenciarse a la de un niño ya que tienen gorro y saco.

\section{Consideraciones finales}

Este trabajo presentó algunos de los focos de análisis mas relevantes, para un estudio genealógico de los infantes masculinos a través de los textos escolares: cuáles han sido, cuáles son y qué iconografía y discursos les han dado origen. A partir de los datos aportados, en este trabajo que se encuentra en su fase inicial, pareciera que desde fines de la década del ' 60 del siglo XX los textos permiten identificar transformaciones significativas respecto a la diferencia sexual. Los roles asignados a la mujer y al varón,

\footnotetext{
${ }^{11}$ Entre la década del 40 y 50 hay lecturas sobre los pantalones largos.

${ }^{12}$ Continuamente se cita en las lecturas dedicadas al pasaje de niño a hombre la importancia de "estar preparado para...."
} 
la vestimenta, los usos del cuerpo, los gestos y movimientos, los atributos morales, entre otros. Esta serie de cambios implican la configuración de un nuevo escenario de relaciones de saber y poder entre ambos colectivos. Se ha intentado demostrar que ciertos mecanismos vinculados a la construcción de la masculinidad en las instituciones escolares, dejan de ser preponderantes y otros se instalan en su lugar. En esta última línea se pretende continuar este estudio, profundizando el análisis aquí presentado pues, sin dudas, la institución escolar continúa produciendo cuerpos generizados.

La evidencia contribuye a alimentar la tesis sostenida por el pedagogo Mariano Narodowski (1999), en tanto que en la modernidad el ser niño era solamente "esperar a ser adulto, preparándose para el momento en que ello aconteciera. Momento que se mostraba con ceremonias de iniciación diversas: los pantalones largos, una excursión al prostíbulo, la fiesta de quince años, el reloj de oro, el primer sueldo, el ingreso al servicio militar. La infancia era la espera; ser niño solamente consistía en esperar" ${ }^{13}$.

Por otra parte, a partir de esos mismos años, aunque en forma mas evidente, a partir de los años '80 del siglo XX, las prescripciones sobre usos del cuerpo y acciones hacia los infantes masculinos decrecen de manera significativa. Se opera un desplazamiento hacia otras actitudes, posturas corporales, otras vinculaciones entre niños y niñas: en los que la investigación, indagación, descubrimiento, tolerancia y convivencia, pasan a ocupar el centro de las lecturas escolares. Resultados tal vez como afirma Gilles Lipovetsky (1994) del rechazo del deber austero propio de una "sociedad posmoralista" consagrada a la explosión y satisfacción de los deseos, a la búsqueda de la felicidad y del placer, en la que una "moral de la obligación" ha sido reemplazada por la "moral del sentimiento".

\section{Bibliografía}

Andrada, M. (2000, setiembre). Happy families according to the shoolbooks used in primary school in Argentina. Ponencia presentada en la XXII th. International Standing Conference for the History of Education, Alcalá de Henares.

Badinter, E. (1981) ¿Existe el amor maternal? Historia del amor maternal. Siglos

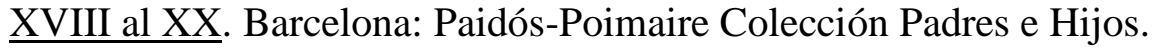

\footnotetext{
${ }^{13}$ Narodowski, M. (1999) El lento camino de la desinnfantilización. En Después de clase. Desencantos y desafíos de la escuela actual. Bs. As. : edu causa, Novedades Educativas, p. 47.
} 
Badinter, E. (1993) XY La identidad masculina._Madrid: Alianza.

Ball S., (Ed.) (1993). Foucault y la educación. Disciplinas y saber. Madrid: Morata.

Bourdieu, P. (2000). La dominación masculina. Barcelona: Anagrama.

Connell, R. (1997). La organización social de la masculinidad. en Valdés, T. y J. Olavarría (Eds.), Masculinidad/es. Poder y Crisis. Santiago: Ediciones de la Mujer, No 24, Isis Internacional y FLACSO.

Connell, R. (1998). El imperialismo y el cuerpo de los hombres, en Valdés, T. y J. Olavarría (Eds.) Masculinidades y equidad de género en América Latina, FLACSO, Santiago.

Elías, N. (1987). El proceso de civilización. México: Fondo de Cultura Económica.

Foucault, M. (1986). Vigilar y castigar. Nacimiento de la prisión.(5ta. edic.) Madrid: Siglo XXI.

Lipovetsky, G. (1994). El crepúsculo del deber. La ética indolora de los nuevos tiempos democráticos. Barcelona: Anagrama Colección Argumentos.

Narodowski, M. (1994). Infancia y poder. La conformación de la pedagogía moderna, Buenos Aires: Aique.

Narodowski, M. (1997) La utilización de periodizaciones macropolíticas en Historia de la Educación. Algunos problemas. En Martínez Boom, A. y Narodowski, M. (Eds.), Escuela, Historia y Poder. Miradas desde América Latina,. Buenos Aires: Novedades Educativas.

Narodowski, M. (1999). Después de clase. Desencantos y desafíos de la escuela actual, Colección edu/causa, Novedades Educativas, Buenos Aires.

Santa Cruz, M., Femenias, M. et. al, (1994). Aportes para una crítica de la teoría de género. En Mujeres y Filosofía (I). Teoría filosófica de género. Buenos Aires: CEAL.

Scharagrodsky, P. (2000). Cuerpo, Género y Poder en la escuela. La construcción de la masculinidad en las clases de Educación Física. Tesis de presentada para obtener el título de Master en Ciencias Sociales con Orientación en Educación cohorte 1997-1999, Facultad Latinoamericana de Ciencias Sociales, Buenos Aires, Argentina.

Turner, B. (1984). The Body and Society. Explorations in Social Theory. OxfordNueva York: Basil Blackwell.

Varela, J. (1997). Nacimiento de la mujer burguesa. El cambiante desequilibrio de poder entre los sexos. Madrid: La Piqueta.

Vigarello, G. (1991) Lo limpio y lo sucio. La higiene del cuerpo desde la Edad Media. Madrid: Editorial Alianza.

Wainerman, C. y Heredia, M. (1999). ¿Mamá amasa la masa?. Cien años en los libros de lectura de la escuela primaria. Buenos Aires: Editorial de Belgrano.

\section{Fuentes consultadas}

Libros de texto de primaria argentinos. 